\title{
Novel insights into renovascular hypertension and cardio-renal protection by iron restriction
}

\author{
Atsushi Tanaka and Koichi Node \\ Hypertension Research (2016) 39, 829-831; doi:10.1038/hr.2016.121; published online 8 September 2016
}

$\mathrm{I}^{\mathrm{I}}$

ron is one of the essential elements and has 1 pivotal roles in biological systems. In particular, iron is needed for the growth and synthesis of hemoglobin; a shortage of iron is associated with the development of iron deficiency anemia. Because this pathological condition is associated closely with increased morbidity and mortality in patients with heart failure, ${ }^{1}$ oral iron supplements are often administered to treat iron deficiency. A shortage of iron is therefore a more common focus in the clinical setting than excess of iron, which tends to be less recognized. Excess accumulation of iron can lead to increased production of reactive oxygen species (ROS) via Fenton/Haber-Weiss catalytic reactions, and it is therefore important to recognize the clinical importance of appropriate systemic iron balance. Because excess production of ROS may lead to cellular and organ damage, ${ }^{2}$ it is likely that the pathogenesis of cardiovascular disease can be attenuated by iron restriction. This possibility is supported by the finding in apoEknockout mice that an increased burden of iron deposition is associated with the progression of atherosclerosis. ${ }^{3}$ Furthermore, the signal intensity of iron-based magnetic resonance imaging of the arterial wall has been shown to reflect the degree of systemic inflammation in younger women. ${ }^{4}$

Naito et al. ${ }^{5}$ have actively investigated the pathological roles of iron in cardiovascular and renal diseases in several rodent models. In 2011, they first reported that dietary iron restriction (IR) in Dahl salt-sensitive rats fed with a high-salt diet attenuated the development of hypertension, heart failure and aortic

A Tanaka and K Node are at Department of Cardiovascular Medicine, Saga University, Saga, Japan E-mail: node@cc.saga-u.ac.jp remodeling by inhibiting oxidative stress. The authors subsequently demonstrated in a rat model of chronic kidney disease (CKD) that dietary IR prevented or rescued the development of hypertension and renal histopathological damage by inhibiting renal mineralocorticoid receptor (MR) signaling. ${ }^{6,7}$ They also found that dietary IR attenuated renal injury in aldosterone/salt-induced hypertensive mice. ${ }^{8}$ Because iron accumulation is related to dysfunction in various organs, including the kidney, liver and heart, the therapeutic effects of iron chelation by deferoxamine have been investigated. ${ }^{9,10}$ More recently, Naito and coworkers ${ }^{11}$ reported that iron chelation in a CKD rat model inhibited the development of renal interstitial fibrosis and reduced inflammatory biomarkers. These data indicate a potent therapeutic role for iron-targeted dietary and/or pharmacological interventions in cardiovascular and renal diseases.

As reported in the current issue, Oboshi and Naito et al. ${ }^{12}$ further investigated the therapeutic effect of iron restriction on hypertension and renal damage in an established rat model of renovascular hypertension (RVHT) using the Goldblatt two-kidney one-clip (2K1C) method. The $2 \mathrm{~K} 1 \mathrm{C}$ rat develops hypertension and renal hypertrophy in association with tissue remodeling. In contrast, the $2 \mathrm{~K} 1 \mathrm{C}$ rat with dietary IR exhibits attenuation of hypertension at an early phase after the operation and vascular remodeling during the late phase. Although no structural differences were observed in the clipped kidney, the IR regimen suppressed compensatory hypertrophy and decreased superoxide production and urinary $8-\mathrm{OHdG}$ levels in the unclipped kidney. Consistent with Naito and colleagues' previous reports, dietary IR attenuated renal MR signaling and fibrosis in the 2K1C rat. As expected, dietary IR caused severe anemia and a compensatory increase in serum erythropoietin (Epo) levels. Importantly, mild IR (a 30\% iron-restricted diet) also attenuated hypertension, proteinuria and renal remodeling. These results are the first evidence that dietary IR can ameliorate RVHT in $2 \mathrm{~K} 1 \mathrm{C}$ rats.

RVHT is a common type of secondary hypertension that is associated closely with increased oxidative stress. Tanemoto et al. ${ }^{13}$ reported that the prevalence of atherosclerotic renal artery stenosis (ARAS) was $21 \%$ in Japanese patients with risk factors for atherosclerosis, and patients with ARAS and CKD had a higher morbidity from coronary artery disease. Elevated systolic blood pressure and diabetes also contribute to the progression of ARAS. ${ }^{14}$ Therefore, ARAS and atherosclerotic RVHT are linked closely to atherosclerotic risk factors and subsequent diseases in the kidney and other systemic organs, followed by increased morbidity and mortality. Because there is no incremental benefit of adding renal-artery stenting to high-quality medications in patients with ARAS, ${ }^{15}$ novel medical approaches against local and systemic pathophysiology are required to improve the prognosis of these patients. As Naito and colleagues show in the current issue, dietary IR has effectively attenuated the development of hypertension and renal damage in several rodent models. The next step will therefore be application of this treatment in humans. However, we wonder if the progression of iron deficiency anemia caused by IR may have unfavorable effects on patients' quality of life and/or pathological conditions. However, the authors demonstrated successfully that mild IR may also attenuate phenotypes with slightly decreased levels of hemoglobin. 


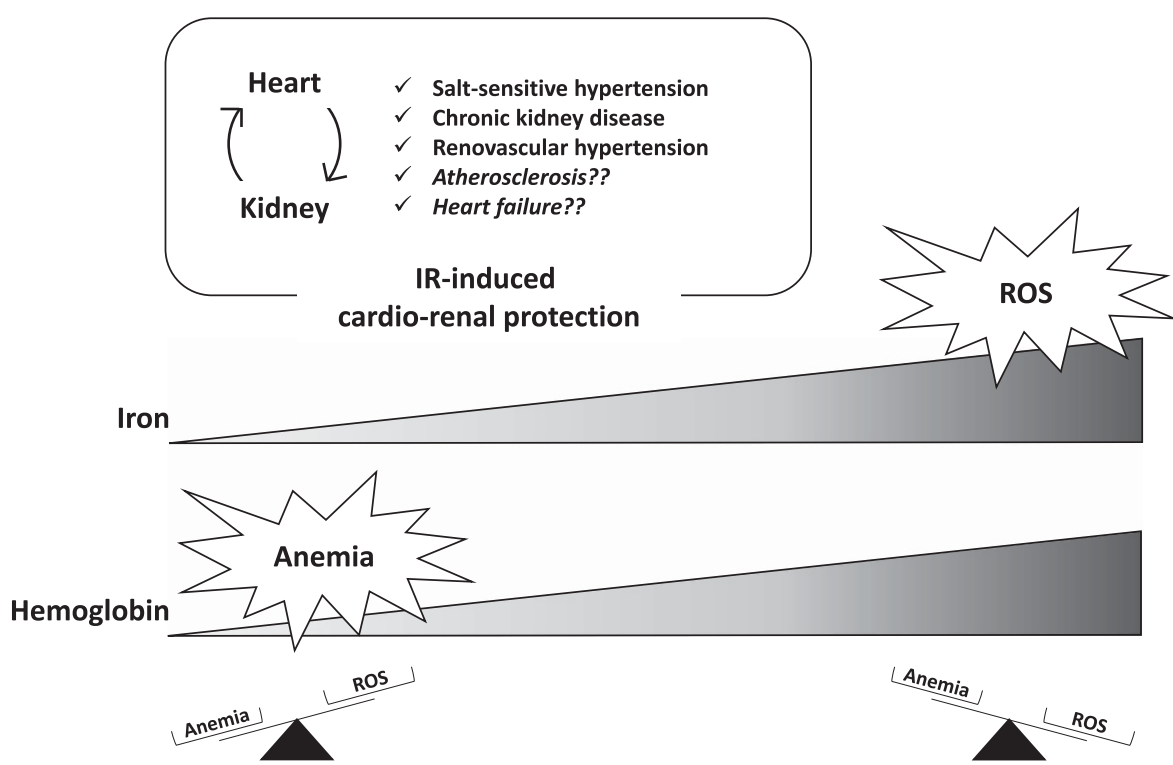

Figure 1 Possible cardio-renal protective effects are induced by dietary iron restriction (IR) through a reduction in oxidative stress in some rodent models, including those with renovascular hypertension. Importantly, an appropriate iron balance in the body is an important issue in cardio-renal association.

Heart failure is often complicated by anemia, which is generally recognized as an exacerbating factor for the condition. Although anemia in patients with heart failure is not necessarily caused by iron deficiency, a lack of iron may adversely affect clinical outcomes in these patients. ${ }^{1}$ Several randomized placebo-controlled clinical trials have demonstrated clearly that intravenous iron therapy improves clinical symptoms in patients with heart failure and iron deficiency. ${ }^{16,17}$ Naito et al. ${ }^{18}$ reported previously that the Epo-cardiac Epo receptor signaling axis is involved in the mechanism of cardiac remodeling, with an anti-apoptotic effect observed following chronic iron deficiency. In addition to iron levels, Epo treatment also improves cardiac function, cardiac remodeling, and clinical symptoms in patients with chronic heart failure and anemia. ${ }^{19,20}$ However, the higher levels of hemoglobin caused by Epo treatment do not reduce the risk of cardiovascular events in patients with CKD. ${ }^{21,22}$ Of note, a trial group with high hemoglobin levels showed an unexpected increase in the risk of death, hospitalization for congestive heart failure and renal replacement therapy. ${ }^{22}$

Given the possible increase in ROS production caused by excessive iron accumulation, the current evidence indicates that the correction of anemia via excessive iron or Epo treatment may not always lead to a reduction in morbidity and mortality, but instead result in worse outcomes for patients with a high risk of cardiovascular events such as those with CKD. Although the precise mechanisms of this adverse effect have yet to be elucidated in humans, excessive iron accumulation and exaggerated Epo signaling are important issues to avoid in certain clinical settings. Importantly, the establishment of appropriate iron and/or Epo signaling levels is clinically required to prevent the development of severe anemia. In addition, the emerging role of dietary IR in cardio-renal association in humans, as proposed by Naito et al., ${ }^{12}$ suggests its potential as an effective treatment with cardio-renal protective action (Figure 1).

\section{CONFLICT OF INTEREST}

$\mathrm{KN}$ has received honoraria from Boehringer Ingelheim, Daiichi Sankyo, Astellas, MSD, Takeda, Mitsubishi Tanabe and Sanofi as well as research grants from Sanwa Kagaku Kenkyusho, Astellas, Takeda, Boehringer Ingelheim, Bayer, Teijin Pharma and Mitsubishi Tanabe. The remaining author declares no conflict of interest.

1 Jankowska EA, von Haehling S, Anker SD, Macdougall IC, Ponikowski P. Iron deficiency and heart failure: diagnostic dilemmas and therapeutic perspectives. Eur Heart $J$ 2013; 34: 816-829.

2 Al-Magableh MR, Kemp-Harper BK, Hart JL. Hydrogen sulfide treatment reduces blood pressure and oxidative stress in angiotensin II-induced hypertensive mice. Hypertens Res 2015; 38: 13-20.

3 Lee TS, Shiao MS, Pan CC, Chau LY. Iron-deficient diet reduces atherosclerotic lesions in apoE-deficient mice. Circulation 1999; 99: 1222-1229.

4 Raman SV, Sharkey-Toppen TP, Tran T, Liu JX, McCarthy B, He X. Smart S, Gulati M, Wexler R, Simonetti OP, Jackson RD. Iron, inflammation and atherosclerosis risk in men vs. perimenopausal women. Atherosclerosis 2015; 241: 249-254.

5 Naito Y, Hirotani S, Sawada H, Akahori H, Tsujino T, Masuyama T. Dietary iron restriction prevents hypertensive cardiovascular remodeling in Dahl saltsensitive rats. Hypertension 2011; 57: 497-504.
6 Naito Y, Fujii A, Sawada H, Hirotani S, Iwasaku T, Eguchi A, Ohyanagi M, Tsujino T, Masuyama T. Effect of iron restriction on renal damage and mineralocorticoid receptor signaling in a rat model of chronic kidney disease. J Hypertens 2012; 30: 2192-2201.

7 Naito Y, Fujii A, Sawada H, Hirotani S, Iwasaku T, Okuhara $Y$, Eguchi A, Ohyanagi M, Tsujino T, Masuyama T. Dietary iron restriction prevents further deterioration of renal damage in a chronic kidney disease rat model. J Hypertens 2013; 31: 1203-1213.

8 Sawada $\mathrm{H}$, Naito $\mathrm{Y}$, Oboshi M, Iwasaku T, Okuhara $\mathrm{Y}$, Morisawa D, Eguchi A, Hirotani S, Masuyama T. Iron restriction inhibits renal injury in aldosterone/saltinduced hypertensive mice. Hypertens Res 2015; 38: 317-322.

9 Ritter C, Reinke A, Andrades M, Martins MR, Rocha J, Menna-Barreto S, Quevedo J, Moreira JC, Dal-Pizzol F. Protective effect of $\mathrm{N}$-acetylcysteine and deferoxamine on carbon tetrachloride-induced acute hepatic failure in rats. Crit Care Med 2004; 32 : 2079-2083.

10 Reddy BR, Kloner RA, Przyklenk K. Early treatment with deferoxamine limits myocardial ischemic/ reperfusion injury. Free Radic Biol Med 1989; 7: 45-52.

11 Naito Y, Fujii A, Sawada H, Oboshi M, Iwasaku T, Okuhara Y, Morisawa D, Eguchi A, Hirotani S, Masuyama T. Association between renal iron accumulation and renal interstitial fibrosis in a rat model of chronic kidney disease. Hypertens Res 2015; 38 : 463-470.

12 Oboshi M, Naito Y, Sawada H, Iwasaku T, Okuhara Y, Eguchi A, Hirotani S, Mano T, Tsujino T, Masuyama T. Attenuation of hypertension and renal damage in renovascular hypertensive rats by iron restriction. Hypertens Res 2016; 39: 832-839.

13 Tanemoto M, Saitoh H, Satoh F, Satoh H, Abe T, Ito S. Predictors of undiagnosed renal artery stenosis among Japanese patients with risk factors of atherosclerosis. Hypertens Res 2005; 28: 237-242.

14 Caps MT, Perissinotto C, Zierler RE, Polissar NL, Bergelin RO, Tullis MJ, Cantwell-Gab K, Davidson RC, Strandness DE Jr. Prospective study of atherosclerotic disease progression in the renal artery. Circulation 1998; 98: 2866-2872.

15 Cooper CJ, Murphy TP, Cutlip DE, Jamerson K, Henrich W, Reid DM, Cohen DJ, Matsumoto AH, Steffes M, Jaff MR, Prince MR, Lewis EF, Tuttle KR, Shapiro JI, Rundback JH, Massaro JM, D'Agostino RB Sr, 
Dworkin LD. Stenting and medical therapy for atherosclerotic renal-artery stenosis. N Engl J Med 2014; 370: 13-22.

16 Anker SD, Comin Colet J, Filippatos G, Willenheimer R, Dickstein K, Drexler $\mathrm{H}$, Luscher TF, Bart B, Banasiak W, Niegowska J, Kirwan BA, Mori C, von Eisenhart Rothe B, Pocock SJ, Poole-Wilson PA, Ponikowski $P$. Ferric carboxymaltose in patients with heart failure and iron deficiency. N Engl J Med 2009; 361: 2436-2448.

17 Ponikowski P, van Veldhuisen DJ, Comin-Colet J, Ertl G, Komajda M, Mareev V, McDonagh T, Parkhomenko A, Tavazzi L, Levesque V, Mori C, Roubert B, Filippatos G, Ruschitzka F, Anker SD. Beneficial effects of long-term intravenous iron therapy with ferric carboxymaltose in patients with symptomatic heart failure and iron deficiency. Eur Heart J 2015; 36: 657-668.

18 Naito $Y$, Sawada $H$, Oboshi M, Iwasaku T, Okuhara $Y$, Morisawa D, Eguchi A, Hirotani S, Mano T, Tsujino T, Masuyama T. Cardiac remodeling in response to chronic iron deficiency: role of the erythropoietin receptor. J Hypertens 2015; 33: 1267-1275.

19 Silverberg DS, Wexler D, Blum M, Keren G, Sheps D, Leibovitch E, Brosh D, Laniado S, Schwartz D, Yachnin T, Shapira I, Gavish D, Baruch R, Koifman B, Kaplan C, Steinbruch $S$, laina $A$. The use of subcutaneous erythropoietin and intravenous iron for the treatment of the anemia of severe, resistant congestive heart failure improves cardiac and renal function and functional cardiac class, and markedly reduces hospitalizations. J Am Coll Cardiol 2000; 35: 1737-1744.
20 Palazzuoli A, Silverberg DS, lovine F, Calabro A, Campagna MS, Gallotta M, Nuti R. Effects of betaerythropoietin treatment on left ventricular remodeling, systolic function, and B-type natriuretic peptide levels in patients with the cardiorenal anemia syndrome. Am Heart J 2007; 154: 645.e9-15.

21 Drueke TB, Locatelli F, Clyne N, Eckardt KU, Macdougall IC, Tsakiris D, Burger HU, Scherhag A. Normalization of hemoglobin level in patients with chronic kidney disease and anemia. N Engl J Med 2006; 355: 2071-2084.

22 Singh AK, Szczech L, Tang KL, Barnhart H, Sapp S, Wolfson M, Reddan D. Correction of anemia with epoetin alfa in chronic kidney disease. N Engl J Med 2006; 355: 2085-2098. 